\title{
Continuity and Trust in Primary Care: A Qualitative Study Informed by Game Theory
}

\author{
Carolyn Tarrant, $P b D^{1}$ \\ Mary Dixon-Woods, MSc, DipStat \\ $D P b i l^{1}$
}

Andrew M. Colman, $\mathrm{PbD}, \mathrm{FBP}_{\mathrm{s}} \mathrm{S}^{1}$

Tim Stokes, PbD, FRCGP2

'Department of Health Sciences, University of Leicester, Leicester, United Kingdom

${ }^{2}$ National Primary Care Research and Development Centre, University of Manchester, Manchester, United Kingdom

Conflicts of interest: none reported

\section{CORRESPONDING AUTHOR}

Mary Dixon-Woods, PhD

Department of Health Sciences

2nd Floor, Adrian Bldg

University of Leicester

University Road, Leicester, LE1 7RH

England, UK

md11@le.ac.uk

\begin{abstract}
PURPOSE The relationship between continuity of care and patient trust in primary care is not fully understood. We report an empirical investigation, informed by game theory, of patients' accounts of their trust in general practitioners (GPs).

METHODS We conducted an analysis based on the constant comparative method of 20 semistructured interviews with patients about trust in GPs in the United Kingdom.

RESULTS People use institutional trust, derived from expectations of medicine as an institution and doctors as professionals, as a starting point for their transactions with unfamiliar doctors. This expectation may be enough to allow patients the minimum of what they want from doctors and is often sufficient for singleepisode encounters, where patients have specific goals. Repeated interactions with the same doctor can allow patients to develop more secure expectations, based on a history of other interactions and anticipation of future interactions. Secure trust can develop over time, especially if patients are convinced that the doctor has their interests at heart.
\end{abstract}

CONCLUSIONS This work identifies dynamics inherent in repeated interactions that enable secure trust to develop. These findings have important implications for the design of services, which in the United Kingdom and elsewhere are increasingly focused on enhancing access rather than continuity. They suggest that patients do not see GPs as interchangeable and that the move toward organizing services around single encounters may disrupt the development of secure trust.

Ann Fam Med 2010;8:440-446. doi:10.1370/afm.1160.

\section{INTRODUCTION}

$\mathrm{T}$ This article draws on game theory to help theorize the relationship between continuity of care and patient trust in primary care. Game theory is a formal theoretical framework for analyzing strategic interactions between 2 or more decision makers who, in the terminology of game theory, are called players. ${ }^{1}$ Game theory was originally developed by mathematicians in the 1920 s, and its original objective was to specify how rational players will act and what outcomes will therefore result in particular games. Players are assumed to be rational only in the weak sense that they invariably act in their own best interests relative to their current knowledge and beliefs. Later developments of game theory, especially behavioral game theory, ${ }^{2-4}$ explicitly recognize the bounded rationality of human decision makers and have found wide application in the social and behavioral sciences. ${ }^{1,5,6}$

Game theory work makes an especially interesting and important contribution to refining understanding of features of trust and cooperation in relationships by proposing and testing sophisticated models of the relevance and contribution of a range of psychological, social, and 
institutional factors. ${ }^{2,3,6}$ This work suggests that social norms, awareness of others' reputations, and signals of trustworthiness from verbal and nonverbal communication influence decisions about trust and cooperation, alongside the structural and dynamic aspects of the situations within which individuals interact. Given the relevance of trust and cooperation to health care, there is evident potential for application of game theory concepts and principles to help theorize many aspects of interactions in health settings. With a few exceptions, ${ }^{7-9}$ however, it has remained neglected within the health sciences. We propose that game theory is potentially valuable in explaining many empirically observed phenomena in health care, including the impact of structural and organizational models of health care provision on aspects of trust in professional-patient relationships, particularly where those models have implications for continuity of care.

UK primary care is an important area for the study of such phenomena because recent policy shifts have emphasized the enhancement of access and choice rather than sustaining long-term interpersonal relationships as the key aspiration; at the same time, they have promoted the notion of health professionals being interchangeable. Patients no longer register with a particular general practitioner $(\mathrm{GP})$; instead, they register with a group practice. GPs are no longer obliged to provide 24-hour care for their patients, and responsibility for after-hours care is predominantly delegated elsewhere, usually to health professionals who have no prior acquaintance with the individual patients. Patients are also encouraged to use a range of primary care services, including walk-in centers, NHS Direct (a National Health Service telephone help line), and pharmacists. Who provides care is therefore increasingly seen as at policy level as less important than where and when. These changes in institutional patterns of primary care provision have led to concerns that disrupting continuity in primary care may undermine trust. ${ }^{10}$ Trust is often considered a critical aspect of health professionalpatient interactions; apart from its intrinsic value, it is associated with desirable outcomes, including patient satisfaction, adherence to treatment or advice, and perceived effectiveness of care. ${ }^{11-15}$

Notwithstanding the effort given to describing and modeling the development of trust over time, ${ }^{16-24}$ the mechanisms underlying the relationships between aspects of continuity and trust are still not fully understood. For example, the extent to which the quality of the GP-patient relationship depends upon longitudinal continuity is unclear. ${ }^{17,25,26}$ A key problem is that empirical research into continuity of care has lacked an integrative theory, ${ }^{24}$ making it difficult to offer a conceptually sophisticated answer to the question of whether continuity of care from the same GP over time really matters for patient trust, and if so, why.

Game theory addresses this lacuna. It is especially relevant to thinking about continuity because of the distinction it makes between the properties of singleepisode interactions (or games) on the one hand and repeated interactions on the other. Experimental evidence in game theory shows how the dynamics of repeated interactions provide a context that facilitates and enhances the development of secure trust and lasting cooperation. ${ }^{1,27}$ It further suggests that stable mutual cooperation often depends on individuals having the opportunity to build a history of cooperative encounters, and that cooperative and trustworthy behaviors are incentivized by the anticipation of longterm reciprocal benefits (the so-called shadow of the future) when repeated interactions are anticipated., 727 The nature of single encounters, in contrast, is thought to limit the extent to which secure trust and stable cooperation can be established; individuals have no expectations of each other's behavior, and any incentive to cooperate or to maintain a reputation of trustworthiness for possible future gain is necessarily lacking. ${ }^{27}$

In this article, we report the results of a qualitative study designed to interrogate patient accounts of their trust in GPs. We compare and contrast accounts of trust in single encounters with accounts of trust in repeated interactions. Our study is not intended to provide a test of predictions based on game theory; rather, game theory provides a set of sensitizing concepts $^{28}$ for qualitative data analysis.

\section{METHODS}

Our analysis was based on semistructured interviews with 20 general practice patients conducted as part of a larger qualitative study into the meaning of "personal care" in UK general practice. ${ }^{29}$ Research Ethics Committee approval was granted for the study. In the original study, 40 participants were purposively sampled from 6 general practices in Leicestershire, United Kingdom, varying in terms of locality, size, deprivation, and proportion of patients from ethnic minority groups. Participants were interviewed faceto-face in their own homes. Interviews were conducted by 2 social scientists trained in qualitative research ( 1 of whom is an author of this article, C.T.). The interview topic guide included open-ended questions asking patients to describe their recent experiences of consulting in general practice and to talk about their relationships with their usual GP and with unfamiliar GPs. Specific questions about trust were not asked in interviews, but when issues of trust arose in participants' accounts, they were encouraged to talk about 
their experiences in relation to trust, the meanings they ascribed to it, and its relevance to their relationships with GPs. Interviews were tape-recorded and transcribed verbatim.

As trust emerged as a core theme in participants' accounts of their relationships and encounters with GPs, it was decided to select a subsample for in-depth and focused analysis. Interviews were purposively selected to allow a range of age, sex, ethnicity, locality, and health status. Purposive sampling ensured that the interviews selected came from a heterogeneous group of patients with diverse experiences of illness and of general practice, allowing the phenomenon of trust to be explored in a broad context, not as it applied to specific groups of patients.

Analysis was based on the constant comparative method. ${ }^{30}$ Initial open codes were generated from the text. Key concepts from behavioral game theory served as sensitizing concepts ${ }^{28}$ used to guide, but not constrain, coding, these included notions of single vs repeated interactions, reputation, reciprocity, anticipation of the future, and influencing factors on trust, such as evidence of past trustworthy behavior and verbal and nonverbal cues. Disconfirming cases were sought. Codes were grouped into a set of organizing themes, then storylines ${ }^{31}$ and concept maps ${ }^{32}$ were used to identify relationships between subthemes. Coding and analysis were undertaken by the first author (C.T.), with checks on coding and interpretation made by 2 additional authors (T.S. and A.M.C.) Analysis was facilitated by the use of the ATLAS.ti software package, version 4.1 (ATLASti, GmbH, Berlin, Germany). Twenty interviews were subject to this detailed analysis, and this sample size was sufficient to reach theoretical saturation.

\section{RESULTS}

Of the 20 participants included in the analysis; 2 were younger than 20 years, 7 were aged between 21 and 40 years, 6 were aged between 41 and 60 years, and 5 were older than 60 years. There were 8 men and 12 women. Thirteen identified themselves as white, English, or British, 6 as South Asian, and 1 as black Caribbean. Eleven participants had chronic health conditions.

\section{Trust in a Single-Episode Consultation}

As an initial starting point for transactions with doctors whom they were to meet for the first (and possibly only) time, participants described relying primarily on what Mechanic ${ }^{33}$ describes as social or institutional trust (ie, trust in institutions, such as the health care system, the medical profession, or an organization). For participants, it made sense to be optimistic about doctors' skills and competence, since they wanted access to their expertise and wanted treatment. This form of trust was functional, in the sense that it enabled patients to get things done.

If something severe happened, and I had to have surgery or something, I'd have to have that confidence in a doctor for them to do it, because I'm not gonna know that surgeon cause I'm not gonna have seen them before, and I'd have to have that confidence with them (interview 5).

This trust was strongly grounded in beliefs that doctors would be suitably qualified; professional credentials acted as warrants of trust ${ }^{34}$ and enabled a way of orienting toward doctors as an institution.

You have to have that confidence in them... because they wouldn't be a doctor, they wouldn't have the qualifications that, you know, everything that goes with being a doctor, they wouldn't have all that. They'd have to have got there somehow (interview 5).

Institutional trust was often sufficient for patients, because it allowed them to access the minimum of what they wanted from doctors-practical outcomes, such as treatment, sickness certificates, diagnoses, referrals, etc. Participants were often prepared to accept anyone for some types of health problems, especially urgent or minor problems, or where the patients did not feel the need to be assured of high levels of competence or good interpersonal skills.

If it was an injury type thing that you needed to go to the doctor for, then it wouldn't matter to me who I saw because I'd feel confident that even if it was a locum, the junior doctor, a first day there, I would feel confident that they have had the experience of how to deal with a strained muscle or something like that (interview 3 ).

Describing the trust that patients bring to the consultation as blind or naïve, ${ }^{35}$ however, would seem a deficient way of conceptualizing how participants in our study oriented themselves toward GPs. Rather than uncritical acceptance that all doctors would be equally trustworthy, many participants attended to other cues and signs, including heuristics, such as group membership and reputation, to determine whether to trust a particular GP: "They all speak very highly of him.... They tell me that the man doctor's very, very good" (interview 9).

We found examples of patients who were not wholly optimistic when consulting an unfamiliar GP. These patients did not withhold trust, but they were more skeptical and open to the possibility of disappointment. Heuristics and reputation could therefore operate to undermine, rather than secure, trust-as in the case of a female South Asian patient, who, though she had not met any of them, described how she did 
not trust the GPs at a practice because they were all older South Asian men. For others, wariness derived from their own dispositional characteristics, previous experiences of untrustworthy GPs, or a sense of acute personal vulnerability.

I was quite anxious... because I had just become pregnant, and I had received 5 years' fertility treatment... So it was quite an important time for me. It was fine but you don't know that and it makes you quite uneasy...what's he like (interview 1)?

Once a doctor had been accessed, effective communication and development of common understanding during the consultation could help to develop what Meyerson et al refer to as swift trust ${ }^{36}$ in a single encounter:

If you go and see any doctor for the first time... if you get the proper treatment... if he has got a listening ear, if he's calm, if he asks the patient politely, "What's wrong?". . .you reinforce your trust in him (interview 6).

Swift trust was fragile and easily undermined, however, by perceived breaches of expectations about GPs' motivation or competence.

His general attitude, I felt, wasn't a pleasant attitude, and he wanted you to leave as quickly as possible.... I just felt that he really wasn't bothered at all... I remembered feeling I don't ever want to see that man again (interview 12).

These findings are consistent with the game theory suggestion that there is little inherent in a single interaction to provide a foundation for secure trust. In this context, people can draw only on whatever general information is available as to the likely trustworthiness of the person with whom they are interacting, such as social role and group membership (including the assurances inherent in the social role of doctor), and cues to trustworthiness derived from aspects of verbal and nonverbal communication. ${ }^{4}$ Trust in single encounters can be functional, but it is fragile and limited in scope.

\section{Repeated Interactions and Trust}

Many patients preferred to see trust as an integral part of an ongoing relationship with a GP. Consulting a GP repeatedly, as would be suggested by game theory, ${ }^{4,27}$ provided the opportunity to amass cumulative experiences of trustworthy behavior and establish norms of cooperation and reciprocity. Two features seemed especially important to patients as elements of a doctors' trustworthy behavior over time: the extent to which GPs seemed competent, and the extent to which they appeared to act in the patient's interests. ${ }^{37}$

Participants mostly tended to begin from the assumption that GPs would be competent, and their trust was maintained and reinforced if they perceived that the care they received was appropriate and effective, or if GPs demonstrated awareness of the limits of their expertise:

Well, very much having confidence in the doctor... You see he discovered this angina, well, I don't say he discovered it, but I mean he immediately sent me to hospital (interview 2).

In the same way, trust could be undermined by breaches of expectations about competence, especially evidence of misdiagnosis: "I've been to a particular doctor at the practice who has misdiagnosed.... I wouldn't have any confidence in him" (interview 17).

Evidence of the GP's motivation to put the interests of the patient first was core to the development of trust. For participants, strong evidence of trustworthiness was provided when a GP seemed intrinsically motivated to care for patients, was willing to invest effort in the patient, showed personal knowledge, was particularly caring, invested time in identifying and resolving their problems, or made an additional effort to help them.

He wants to find out more, which I like, rather than you just telling him that you're ill and he'll give you something. He actually wants to find out what is actually wrong with you (interview 4).

In contrast, trust could be undermined by rushing patients, appearing to be motivated by financial or personal interests, or not demonstrating the orientation toward the patients' welfare that their role required: "All they are concerned about is profit...my doctor he seems more businesslike rather than patients come first" (interview 20). In another reply, "It seems that he was more interested in when he were retiring, than [in] my missus [wife]" (interview 11).

Repeated interactions not only allowed patients to validate the GP as trustworthy but also enabled patients to build their own reciprocal reputation with their GP. Participants described the value of having the opportunity to be validated in the eyes of the GP as legitimate or trustworthy patients who would not abuse or take advantage of the service provided. ${ }^{19,38,39}$ Developing and maintaining this identity as a cooperative patient acted to secure trust, as patients believed that the GP would have good reasons to take them seriously and would be motivated to act in their best interests:

You know he understands that if you're complaining about something, you've jolly well got something and you're not sort of making it up or wasting his time (interview 2).

Again, in contrast, trust could be undermined if the patient felt discredited by the GP, to the extent that patients were unwilling to continue to see the GP in the future. 
This was when she was teething, my daughter... It was really upsetting her and that and she was high with temperature and...I thought I'd just take her in and to the doctors and see if he could give me something a bit stronger to relieve the pain, and he just told me straight, "Well it's up to the parents to look after them properly...." And that really got me (interview 13).

In this way, initial orientations toward GPs were superseded by experiential knowledge that informed patients' level of trust. This finding is consistent with the game theory conclusion that trust can develop over repeated interactions, in which individuals have the opportunity to update their beliefs about each others' trustworthiness. ${ }^{27}$

Not only was past experience important in promoting trust, but expectations of future interactions also played an important role. ${ }^{9}$ Participants described how expectations of future care from the GP, as well as evidence of the GP's commitment to their future care, provided a strong foundation for trust. In contrast, a perception that they would not see the GP again was a reason for patients questioning the extent to which the GP could be trusted to fully act in their best interests.

You may see [doctor] again or something...it's not the sort of feeling_- Oh, I'll give him a pill and go." They're slightly more accountable probably (interview 3).

\section{Value of Secure Trust}

In contrast to the fragile trust relations characterizing single encounters, secure trust built over time tended to be robust, with participants willing to forgive the occasional mistake or to accept a GP's limits without long-term damage to their trust. Once they had built evidence that the GP was motivated to care for them, patients were less likely to attribute errors to a lack of effort or motivation on the part of the doctor.

I think cor, good of the bloke, that he's found time to ring me up and say-well actually more or less apologize to me on the phone that he didn't diagnose what I had got (interview 3).

The kind of trust developed over time tended to engender feelings of confidence and security, which were very highly valued by participants.

As time goes on you get more confidence and you feel more comfortable with them, and you know how they are going to be with you, the sort of responses you are going to get from them, and that makes you feel more comfortable and secure in going to see them (interview 17).

Secure trust stretched further than swift trust and was especially highly valued; patients often felt they needed secure trust where problems were personal or complex, or where they felt they needed an advocate to act in their interests or their situation required someone who they could rely upon to take some extra trouble for them.

I probably go to see other GP's if I got flu and cold or whatever, but Dr X I would go and see her for my personal problems...like after I had her, for the contraception injections I was having, I won't go and see any other doctors. I'll just go and make sure I had an appointment with her (interview 14).

\section{DISCUSSION}

Our analysis suggests that drawing on game theory not only helps to provide a theoretical basis for previous descriptions of the development of the GP-patient relationship, ${ }^{40,41}$ it also generates a new set of understandings into the dynamics of trust in encounters and relationships. Patients are often willing to draw on institutional trust as to engage with unfamiliar GPs, consistent with the observation from behavioral game theory that people can and do trust each other enough to cooperate even in single encounters. ${ }^{42}$ This trust is not blind or naïve; rather, it is a handy or convenient heuristic that provides a pragmatic starting point, is provisional and contingent, and can be reinforced or undermined by cues to trustworthiness picked up from interpersonal aspects of the consultation. We found that, on the whole, patients' initial trusting stance tended to be maintained passively as long as assurances were available about the motives and competence of the GP. Evidence that refuted these assumptions could easily destroy trust, perhaps especially in the early stages of relationships.

With repeated positive interactions, however, trust could become more secure as patients amassed experience of the GP and built their own reputations as cooperative and trustworthy. The expectation of future interactions gave patients what they saw as good reasons to trust their GP to act in their best interests. Trust that had been established over time and was set in the context of a relationship that was expected to continue into the future was especially rich and valued by patients. Such trust was more robust to errors and lapses on the part of the GP. In contrast, transactions in single encounters tended to be limited in scope, and patient trust in such encounters was much more precarious and vulnerable to failure. In this sense, as game theory would suggest, repeated interactions between patients and GPs have unique dynamics that can support the development of secure and trust which are not shared by single encounters. ${ }^{7,27}$

The findings of this study may be limited in that the sample consisted of patients from a single county of England. Though the sample was purposively selected to be heterogeneous in terms of patient characteristics 
and experiences of care, it is possible that a different set of views might have been expressed by a different sample. Nonetheless, there are a number of important implications of our findings for choices about the optimal organization of primary care services.

Our study goes beyond simply repeating the finding that there is a relationship between continuity and trust. By developing a theoretically based account of trust in relationships and encounters, our analysis helps to explain how and under what circumstances trust can be reinforced or undermined over time. Further, rather than focusing solely on past experience as the relevant dimension of continuity, as is the norm in the current literature, an analysis animated by game theory demonstrates that continuity has both a past and a future dimension, ${ }^{43}$ thus improving understanding of the role of the longitudinal dimensions of the doctor-patient relationship in the development of trust.

Our study also provides new insights into the complexities of continuity and avoids valorizing continuity as necessarily a good thing. ${ }^{44}$ Our findings suggest that repeated interactions over time are not in themselves sufficient to develop secure trust. Though some degree of longitudinality ${ }^{17}$ is needed, the development of trust is also dependent on what happens in interactions. We found some instances where trust was not built or was undermined despite repeated interactions, particularly where patients believed the GP was not motivated to act in their best interests or where they had concerns about quality of care. We would not expect continuity as measured by such indicators as frequency of visits or proportion of visits to the usual doctor ${ }^{45}$ to be necessarily associated with increased trust. ${ }^{17,25}$ Rather, we argue that, as game theory would predict, a history of past interactions and the anticipation of future interactions provide a context that makes it possible for trust to build and become secure. Our work sheds light on the specific features of ongoing relationships that are likely to build or undermine trust by identifying some ways patients assure themselves of the doctor's competence and motivation.

This analysis is important because recent changes to primary care mean that continuity is under threat. Primary health care is more often being provided through transactions between patients and unfamiliar health professionals, and in addition to structural and organizational changes, a loss of continuity of care between patients and GPs has been one of the consequences of the Quality and Outcomes Framework scheme used for incentivizing performance of general practices in England. ${ }^{46}$ Our study shows that patients can still interact with doctors, even if they only see them once. Even so, the form of trust characteristic of such encounters is limited and may be insufficient to enable patients to have some aspects of their health care needs met. Patients do not see GPs as interchangeable, and organizing services around singleepisode encounters may disrupt the development of secure trust. We suggest that when and where care is accessed remain important, but a renewed recognition of the importance of who is consulted is required. Efforts should be made to design and deliver primary care in a way that enables patients to build relationships with GPs over time, in particular by enabling patients to be able to access their preferred GP when they want and need to ${ }^{47}$ alongside other primary care professionals where appropriate.

To read or post commentaries in response to this article, see it online at http://www.annfammed.org/cgi/content/full/8/5/440.

Key words: Continuity of care; trust; game theory; professional-patient relations; primary health care; qualitative research; secure trust

Submitted October 30, 2009; submitted, revised March 2, 2010; accepted March 15, 2010

Funding support: The study from which these data were derived was funded by Trent National Health Service Executive's Policy and Practice RED program; the writing of this article was funded by Carolyn Tarrant's Wellcome Trust Value in People award, and by Mary DixonWoods' fellowship under the Economic and Social Research Council's Public Services Programme (reference RES-153-27-0009) .

Portions of this report were previously presented at the Society for Academic Primary Care, Personal Care Special Interest Group, July 17, 2007, London, England.

Acknowledgments: We thank the patients who participated in the study. Kate Windridge conducted some of the interviews reported in this article; we acknowledge her contribution and that of the study team: Richard Baker, Mary Boulton, and George Freeman.

\section{References}

1. Colman AM. Game Theory and its Applications in the Social and Biological Sciences. 2nd ed. London: Routledge; 1995.

2. Camerer CF. Behavioral Game Theory: Experiments in Strategic Interaction. Princeton, NJ: Princeton University Press; 2003.

3. Colman AM. Cooperation, psychological game theory, and limitations of rationality in social interaction. Behav Brain Sci. 2003;26(2):139-153, discussion 153-198.

4. Ostrom E. Toward a behavioral theory linking trust, reciprocity and reputation. In: Ostrom E, Walker J, eds. Trust and Reciprocity: Interdisciplinary Lessons From Experimental Research. New York, NY: Russell Sage Foundation; 2003:9-79.

5. Sugden R. Rational choice: a survey of contributions from economics and philosophy. Econ J. 1991;101(407):751-785.

6. Myatt D, Wallace C. When does one bad apple spoil the barrel? An evolutionary analysis of collective action. Rev Econ Stud. 2008;75(2):499-527.

7. Gutek BA, Bhappu AD, Liao-Troth MA, Cherry B. Distinguishing between service relationships and encounters. J Appl Psychol. 1999; 84(2):218-233. 
8. Tarrant C, Stokes T, Colman AM. Models of the medical consultation: opportunities and limitations of a game theory perspective. Qual Saf Health Care. 2004;13(6):461-466.

9. Tarrant C, Colman AM, Stokes T. Past experience, 'shadow of the future', and patient trust: a cross-sectional survey. Br J Gen Pract. 2008;58(556):780-783, i-vi.

10. Hjortdahl P. Continuity of care-going out of style? Br J Gen Pract. 2001;51(470):699-700

11. Thom DH, Ribisl KM, Stewart AL, Luke DA; The Stanford Trust Study Physicians. Further validation and reliability testing of the Trust in Physician Scale. Med Care. 1999;37(5):510-517.

12. Thom DH, Kravitz RL, Bell RA, Krupat E, Azari R. Patient trust in the physician: relationship to patient requests. Fam Pract. 2002;19(5):476-483.

13. Benson J, Britten N. Patients' decisions about whether or not to take antihypertensive drugs: qualitative study. BMJ. 2002;325 (7369):873-878.

14. Baker R, Mainous AG III, Gray DP, Love MM. Exploration of the relationship between continuity, trust in regular doctors and patient satisfaction with consultations with family doctors. Scand J Prim Health Care. 2003;21(1):27-32.

15. Safran DG, Taira DA, Rogers WH, Kosinski M, Ware JE, Tarlov AR. Linking primary care performance to outcomes of care. J Fam Pract. 1998;47(3):213-220.

16. Thom DH, Campbell B. Patient-physician trust: an exploratory study. J Fam Pract. 1997;44(2):169-176.

17. Caterinicchio RP. Testing plausible path models of interpersonal trust in patient-physician treatment relationships. Soc Sci Med. 1979;13A(1):81-99.

18. McAllister DJ. Affect- and cognition-based trust as foundations for interpersonal cooperation in organisations. Acad Manage J. 1995;38(1):24-59.

19. Mechanic D, Meyer S. Concepts of trust among patients with serious illness. Soc Sci Med. 2000;51(5):657-668.

20. Thorne SE, Robinson CA. Guarded alliance: health care relationships in chronic illness. J Nurs Scholarsh. 1988;21(3):153-157.

21. Lewicki RJ, Bunker BB. Developing and maintaining trust in work relationships. In: Kramer RM, Tyler TR, eds. Trust in Organisations: Frontiers of Theory and Research. Thousand Oaks, CA: Sage; 1996:114-139.

22. Rousseau DM, Sitkin S, Burt RS, Camerer C. Not so different after all: A cross disciplinary view of trust. Acad Manage Rev. 1998;23 (3):1-12.

23. Lewicki RJ, Tomlinson EC, Gillespie N. Models of interpersonal trust development: Theoretical approaches, empirical evidence, and future directions. J Manage. 2006;32(6):991-1022.

24. Goudge J, Gilson L. How can trust be investigated? Drawing lessons from past experience. Soc Sci Med. 2005;61(7):1439-1451.

25. Mainous AG III, Baker R, Love MM, Gray DP, Gill JM. Continuity of care and trust in one's physician: evidence from primary care in the United States and the United Kingdom. Fam Med. 2001;33(1):22-27.

26. Kao AC, Green DC, Davis NA, Koplan JP, Cleary PD. Patients' trust in their physicians: effects of choice, continuity, and payment method. J Gen Intern Med. 1998;13(10):681-686.

27. Axelrod R. The Evolution of Cooperation. New York, NY: Basic Books 1984.

28. Charmaz K. Constructing Grounded Theory: A Practical Guide Through Qualitative Analysis. London: Sage Publications; 2006.
29. Tarrant C, Windridge K, Boulton M, Baker R, Freeman G. Qualitative study of the meaning of personal care in general practice. BMJ. 2003;326(7401):1310-1317.

30. Glaser BG, Strauss AL. The Discovery of Grounded Theory: Strategies For Qualitative Research. New York, NY: Aldine; 1967.

31. Strauss A, Corbin J. Basics of Qualitative Research: Techniques and Procedures for Developing Grounded Theory. 2nd ed. Thousand Oaks, CA: Sage; 1998.

32. Daley BJ. Using concept maps in qualitative research. In: Proceedings of the First International Conference on Concept Mapping. September 14-17, 2004; Pamplona, Spain; 2004:191-197.

33. Mechanic D. Changing medical organization and the erosion of trust. Milbank Q. 1996;74(2):171-189.

34. Misztal BA. Trust in Modern Societies: The Search for the Bases of Moral Order. Cambridge, UK: Polity Press; 1996.

35. Hall MA, Dugan E, Zheng B, Mishra AK. Trust in physicians and medical institutions: what is it, can it be measured, and does it matter? Milbank Q. 2001;79(4):613-639, v.

36. Meyerson D, Weick KE, Kramer RM. Swift trust and temporary groups. In: Kramer RM, Tyler TR, eds. Trust in Organizations: Frontiers of Theory and Research. Thousand Oaks, CA: Sage Publications; 1996:166-195.

37. Calnan M, Rowe R. Trust in Health Care: An Agenda for Future Research. London: The Nuffield Trust; 2004.

38. Guthrie B. Trust and asymmetry in general practitioner-patient relationships in the United Kingdom. In: Brownlie J, Green A, Howson A eds. Researching Trust and Health. London: Routledge; 2008:133-151.

39. Stokes T, Dixon-Woods M, Windridge KC, McKinley RK. Patients' accounts of being removed from their general practitioner's list: qualitative study. BMJ. 2003;326(7402):1316-1319.

40. Ridd M, Shaw A, Lewis G, Salisbury C. The patient-doctor relationship: a synthesis of the qualitative literature on patients' perspectives. Br J Gen Pract. 2009;59(561):268-275.

41. Gore J, Ogden J. Developing, validating and consolidating the doc tor-patient relationship: the patients' views of a dynamic process. Br J Gen Pract. 1998;48(432):1391-1394.

42. Pruitt DG, Kimmel MJ. Twenty years of experimental gaming: Critique, synthesis, and suggestions for the future. Annu Rev Psychol. 1977;28:363-392.

43. Tarrant C, Stokes T, Baker R. Factors associated with patients' trust in their general practitioner: a cross-sectional survey. $\mathrm{Br} J \mathrm{Gen}$ Pract. 2003;53(495):798-800

44. Chew-Graham CA, May CR, Roland MO. The harmful consequences of elevating the doctor-patient relationship to be a primary goal of the general practice consultation. Fam Pract. 2004;21(3):229-231.

45. Breslau N, Reeb KG. Continuity of care in a university-based practice. J Med Educ. 1975;50(10):965-969.

46. Campbell SM, Reeves D, Kontopantelis E, Sibbald B, Roland M. Effects of pay for performance on the quality of primary care in England. N Engl J Med. 2009;361(4):368-378.

47. Boulton M, Tarrant C, Windridge K, Baker R, Freeman GK. How are different types of continuity achieved? A mixed methods longitudinal study. Br J Gen Pract. 2006;56(531):749-755.

48. Guthrie B, Wyke S. Personal continuity and access in UK general practice: a qualitative study of general practitioners' and patients' perceptions of when and how they matter. BMC Fam Prac. 2006;7:11. 